\title{
At the threshold of a new era in pediatric ventricular assist device therapy
}

\author{
Katsuhide Maeda, MD, PhD
}

\author{
From the Department of Pediatric Cardiothoracic Surgery, Stanford University School of Medicine, Stanford, \\ Calif. \\ Disclosures: Author has nothing to disclose with regard to commercial support. \\ Received for publication Jan 12, 2017; accepted for publication Jan 26, 2017; available ahead of print Feb 28, \\ 2017. \\ Address for reprints: Katsuhide Maeda, MD, PhD, Cardiothoracic Surgery, Stanford University, 300 Pasteur Dr, \\ Stanford, CA 94305 (E-mail: kmaeda@stanford.edu). \\ J Thorac Cardiovasc Surg 2017;154:301-2 \\ $0022-5223 / \$ 36.00$ \\ Copyright (C) 2017 by The American Association for Thoracic Surgery \\ http://dx.doi.org/10.1016/j.jtcvs.2017.01.013
}

The National Institutes of Health Pumps for Kids, Infants and Neonates (PumpKIN) program for pediatric ventricular assist device (VAD) development was first announced in 2004. In this issue of the Journal, Adachi and colleagues ${ }^{1}$ from the Texas Heart Institute report the animal study on a modified miniaturized pediatric continuous-flow device designated as the Infant Jarvik 2015, which is the sole remaining device emerging from the PumpKIN program. The history and the path that the program followed are unique, with multiple social, financial, and medical barriers. ${ }^{1}$ The initial Infant Jarvik 2000 encountered a significant medical issue of excessive hemolysis. After analysis of multiple potential causes, including heating, cavitation, blade clearances, and bearing and material finishes, a solution was devised by modifying the inner rotor and housing size and altering the blade configuration. The new Infant Jarvik 2015 features greater flow range $(0.5-3.0 \mathrm{~L} / \mathrm{min})$, radiused blade tips, and a polyester outflow graft. In vitro study showed a 10-fold reduction in hemolysis relative to the initial Infant Jarvik 2000. After completion of 30 days and 60 days of support in 8 out of 10 sheep, the results appeared favorable. Hematocrit, plasma free hemoglobin, and lactate dehydrogenase were within clinically acceptable ranges in the vast majority of the cases. Unfortunately, these modifications increased the size of the device. The outer diameter of the Infant Jarvik 2015 is $15 \mathrm{~mm}$, compared with $11 \mathrm{~mm}$ in the original Infant Jarvik 2000. This increased size limits the lower size range of patients. According to the virtual fit study performed at Arizona State University and Phoenix Children's Hospital, however, the new device would fit in a $4.3-\mathrm{kg}$ patient if implanted with a subdiaphragmatic pocket. ${ }^{1}$

This new device has some potential advantages and can break barriers that could not be overcome by the Berlin Heart EXCOR (Berlin Heart GmbH, Berlin, Germany), including (1) low quality of life as a result of inability to be discharged, (2) unsatisfactory ventricular decompression and drainage, and (3) high stroke rates as a result of device thrombosis. First, this new device is completely implantable. Currently, patients on Berlin Heart EXCOR support

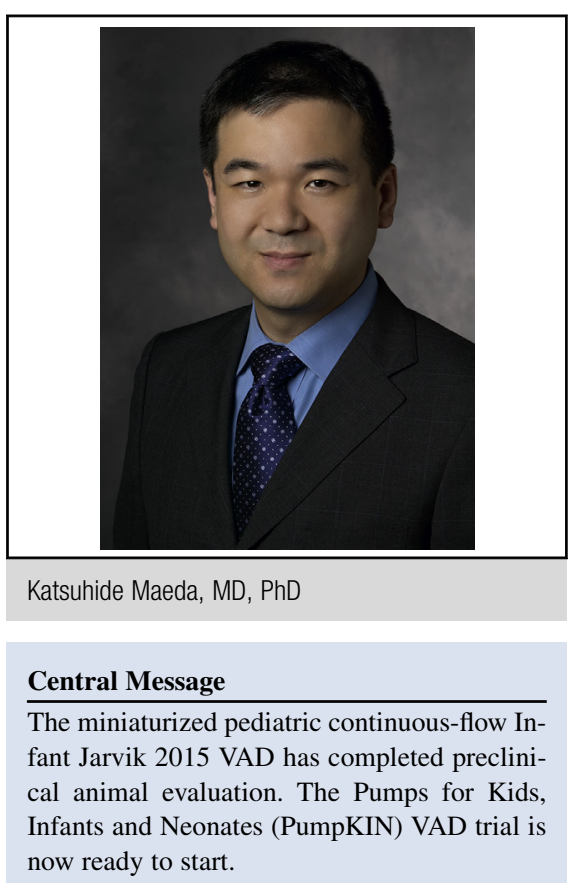

See Article page 291.

have an extracorporeal pump, and they are confined to inhospital support until explantation, which is often for a prolonged period. ${ }^{2}$ This new implantable device has potential to improve this issue dramatically and might even lead to the possibility of home care or eventual destination therapy. Second, this is a continuous-flow pump. Continuous-flow pumps offer advantages of increased reliability, durability and better ventricular decompression, and they have been associated with improvements in survival in adults. ${ }^{3}$ The Infant Jarvik 2015 pump has the potential to launch a paradigm shift in pediatric VAD support. In addition, the continuous-flow pump design is reported to be advantageous in supporting failing single-ventricle physiology, ${ }^{4}$ which currently is one of the most challenging pediatric populations to treat with VAD support. This may provide a better device option for the treatment of these patients. Third, the Berlin Heart EXCOR is associated with a high stroke rate. Jordan and colleagues ${ }^{5}$ reviewed patients supported with the Berlin Heart EXCOR at 47 centers in North America and reported a high stroke rate $(21 \%)$ and a neurologic event rate of 1.86 events/patient-year (recalculated), in contrast to a rate of 0.26 events/patient-year in adult patients supported with continuous-flow devices. ${ }^{6}$ This 
difference may be partially because of patient size, not because of the pulsatile pump, but further human study will clarify this issue.

The major limitation of this study is the use of pigs with normal ventricular function and relatively larger sizes (19$34 \mathrm{~kg})$ than targeted patients $(8-20 \mathrm{~kg})$. Animal study of VADs will never be perfect, however, and results from this investigation indicate that the Infant Jarvik 2015 is ready for transition into human study. For the PumpKIN trial, the actual patient enrollment will begin in January 2017 in 7 Vanguard centers (5 US and 2 Canadian centers). By the time this article has been published, the first Infant Jarvik 2015 VAD may be implanted in a pediatric patient. We hope that this device will improve outcomes of VAD support in small children.

\section{References}

1. Adachi I, Burki S, Horne D, Costas GG, Spangler T, Jarvik R, et al. The miniaturized pediatric continuous-flow device: Preclinical assessment in the chronic sheep model. J Thorac Cardiovasc Surg. 2017;154:291-300.

2. Almond CS, Thiagarajan RR, Piercey GE, Gauvreau K, Blume ED, Bastardi HJ, et al. Waiting list mortality among children listed for heart transplantation in the United States. Circulation. 2009;119:717-27.

3. Cheng A, Williamitis CA, Slaughter MS. Comparison of continuous-flow and pulsatile-flow left ventricular assist devices: is there an advantage to pulsatility? Ann Cardiothorac Surg. 2014;3:573-81.

4. Fujii Y, Ferro G, Kagawa H, Centola L, Zhu L, Ferrier WT, et al. Is continuous flow superior to pulsatile flow in single ventricle mechanical support? Results from a large animal pilot study. ASAIO J. 2015;61:443-7.

5. Jordan LC, Ichord RN, Reinhartz O, Humpl T, Pruthi S, Tjossem C, et al. Neurological complications and outcomes in the Berlin Heart EXCOR pediatric investigational device exemption trial. J Am Heart Assoc. 2015;4:e001429.

6. Stulak JM, Davis ME, Haglund N, Dunlay S, Cowger J, Shah P, et al. Adverse events in contemporary continuous-flow left ventricular assist devices: a multiinstitutional comparison shows significant differences. J Thorac Cardiovasc Surg. 2016;151:177-89. 